\title{
Potencial agronômico e teor de carotenoides em raízes de reserva de mandioca
}

\author{
Agronomic potential and carotenoid contents within cassava storage roots
}

\author{
Karina Nascimento da Silva ${ }^{\mathrm{I}}$ Eduardo Alano Vieira ${ }^{\mathrm{I}}$ Josefino de Freitas Fialho $^{\mathrm{I}}$ \\ Luiz Joaquim Castelo Branco Carvalho ${ }^{\text {II }}$ Marilia Santos Silva ${ }^{\text {II }}$
}

\section{RESUMO}

Os programas de melhoramento genético de mandioca de mesa estão focados na seleção de variedades com a presença de carotenoides nas raizes de reserva. O trabalho foi realizado com o objetivo de avaliar o potencial agronômico e o teor de carotenoides em raizes de reserva de acessos de mandioca com coloração da polpa das raízes creme, amarela e rosada visando à utilização direta por produtores e/ou sua utilização como genitores em programas de melhoramento. Treze acessos de mandioca foram avaliados em experimento conduzido na Embrapa Cerrados por duas safras, quanto aos caracteres altura da primeira ramificação, altura da planta, massa da parte aérea, produtividade de raizes, porcentagem de amido nas raízes, severidade de bacteriose, teor de carotenoides nas raízes, tempo para a cocção em minutos e teor de ácido cianídrico nas raízes. Os resultados evidenciaram a existência de diferenças significativas entre os acessos para os caracteres altura da primeira ramificação, altura da planta, massa da parte aérea, produtividade de raizes, porcentagem de amido nas raizes, severidade de bacteriose e teor de carotenoides nas raizes. Também foram detectadas variações significativas entre as safras e interação significativa entre as safras e acessos para todos os caracteres, com exceção da severidade da bacteriose e do teor de carotenoides nas raizes. Nenhum acesso apresentou desempenho agronômico que justifique o cultivo de forma comercial na região do Cerrado do Brasil Central. Foram detectados acessos com potencial para utilização no melhoramento, visando ao incremento de $\beta$-caroteno BGMC 1221, BGMC BGMC 1223 e BGMC 1224 e de licopeno BGMC 1222 e BGMC 1229 em raizes de reserva.

Palavras-chave: Manihot esculenta Crantz, aipim, melhoramento genético, biofortificação.

\section{ABSTRACT}

The sweet cassava breeding programs are focused on the selection of varieties containing carotenoids within the storage roots. The research was conducted with the objective to evaluate the agronomic potential and the carotenoid contents within the storage roots of cassava accessions with cream, yellow and pinkish color root pulp aiming their potential direct adoption by producers and/or their use as parents for breeding programs. Thirteen cassava accessions were evaluated in an experiment held at Embrapa Cerrados, for two crop seasons, considering the following characters: height of the first ramification, height of the plant, mass of plant canopy, root productivity, starch percentage within roots, bacterial blast severity, carotenoid contents in roots, root cooking time in minutes and cyanidric acid contents within roots. The results demonstrated existence of significant differences among the accessions for height of the first ramification, height of the plant, mass of plant canopy, root productivity, starch percentage within roots, bacterial blast severity and carotenoid contents within roots. Moreover, it was observed significant variations among crop seasons and significant interaction between the crop seasons and accessions for all the characters evaluated, except for bacterial blast severity and carotenoid contents within roots. No accession presented agronomic performance that would justify commercial cultivation within the Cerrado region of Central Brazil. There were accessions identified with potential for use as parents in plant breeding aiming the increment of $\beta$-carotene BGMC 1221, $B G M C B G M C 1223$ and BGMC 1224 and lycopene BGMC 1222 and BGMC 1229 contents in storage roots.

Key words: Manihot esculenta Crantz, cassava, plant breeding, biofortification.

\section{INTRODUÇÃO}

O melhoramento genético de mandioca de mesa (aipim, macaxeira e mandioca mansa) sempre focou no desenvolvimento de variedades com teores de ácido cianídrico $(\mathrm{HCN})$ nas raízes de reserva

IEmbrapa Cerrados, BR 020km 18, 73310-970, Planaltina, DF, Brasil. E-mail: eduardo.alano@embrapa.br. *Autor para correspondência.

IEmbrapa Recursos Genéticos e Biotecnologia, Brasília, DF, Brasil. 
inferiores a $100 \mathrm{mg} \mathrm{kg}^{-1}$, elevada produtividade de raízes de reserva, raízes de reserva com boas qualidades culinárias, como baixo tempo para $\mathrm{o}$ cozimento, poucas fibras, massa não pegajosa, sabor e aroma agradáveis, plantas com arquitetura favorável aos tratos culturais e ao plantio mecanizado, com elevada estatura da primeira ramificação, elevada resistência a pragas e doenças, raízes lisas ou com poucas cintas, entre outros caracteres de importância (FUKUDA et al., 2002).

Atualmente, os programas de melhoramento genético de mandioca de mesa estão focados no desenvolvimento de variedades biofortificadas que aliem aos caracteres citados acima a presença de carotenoides como $\beta$-caroteno nas raízes de coloração amarela (CHÁVEZ et al., 2005; MEZETTE et al., 2009; CARVALHO et al., 2012a; CARVALHO et al., 2012b) e licopeno nas raízes de coloração rosada (CARVALHO et al., 2011). Esses carotenoides apresentam importância na alimentação humana pelos benefícios do $\beta$-caroteno como precursor da vitamina $\mathrm{A}$, no combate a cegueira noturna, distúrbios de crescimento e dificuldade de aprendizagem (UNDERWOOD \& SMITASII, 1999), e do licopeno como antioxidante, no combate ao envelhecimento precoce e na prevenção do câncer de próstata (SHAMI \& MOREIRA, 2004).

Programas de melhoramento genético de mandioca, visando à melhoria das qualidades nutricionais das raízes de reserva necessitam de variabilidade genética e que o germoplasma disponível seja caracterizado e avaliado, objetivando sua utilização de forma direta pelos produtores ou indireta, no desenvolvimento de variedades adaptadas a locais específicos. Estudos realizados vêm demostrando que no germoplasma de mandioca existe variabilidade disponível para esse fim em acessos de mandioca com coloração da polpa das raízes amarelas e rosadas (CHAVÉZ et al., 2005; CARVALHO et al., 2011; VIEIRA et al., 2011; CARVALHO et al., 2012a; CARVALHO et al., 2012b). Entretanto, não existem na literatura estudos visando à caracterização agronômica e quanto ao teor de carotenoides nas raízes desse germoplasma nas condições do Cerrado do Brasil Central, com vistas à utilização direta por parte dos produtores e/ou quanto à utilização no melhoramento genético.

O trabalho foi realizado com o objetivo de avaliar o potencial agronômico e o teor de carotenoides em raízes de reserva de acessos de mandioca com coloração da polpa das raízes creme, amarela e rosada visando à utilização direta por produtores e/ou sua utilização como genitores em programas de melhoramento genético de mandioca de mesa.

\section{MATERIAL E MÉTODOS}

Os experimentos de campo foram conduzidos entre outubro de 2006 e outubro de 2007 (safra 2006/2007) e entre outubro de 2007 e outubro de 2008 (safra 2007/2008) em área experimental da Embrapa Cerrados, localizada no município de Planaltina no Distrito Federal.

O delineamento experimental utilizado foi o de blocos casualizados com três repetições, onde foram avaliados treze acessos de mandioca, mantidos no Banco Regional de Germoplasma de Mandioca do Cerrado (BGMC), listados na tabela 1, sendo quatro com coloração da polpa da raiz rosada, oito com coloração da polpa da raiz amarela e mais a testemunha com coloração da polpa da raiz creme IAPAR 19/Pioneira (BGMC 982), indicada para o cultivo na região do Distrito Federal e entorno (VIEIRA et al., 2009).

Cada parcela foi composta por 4 linhas com 10 plantas em espaçamento de $1,20 \mathrm{~m}$ entre linhas e $0,80 \mathrm{~m}$ entre plantas, sendo a área útil de cada parcela constituída pelas 16 plantas centrais. Todos os tratos culturais foram realizados de acordo com as recomendações técnicas da cultura (FIALHO \& VIEIRA, 2011).

Aos doze meses após o plantio, os experimentos foram colhidos, momento em que foram aferidos os caracteres altura da planta em m; altura da primeira ramificação em m; massa da parte aérea sem a cepa em $\mathrm{kg} \mathrm{ha}^{-1}$; produtividade de raízes em $\mathrm{kg} \mathrm{ha}^{-1}$; porcentagem de amido nas raízes por meio do método da balança hidrostática, descrito por GROSMANN \& FREITAS (1950); tempo para a cocção em minutos, de acordo com o método descrito por BORGES et al. (2002); e teor de ácido cianídrico nas raízes $\left(\mathrm{mg} \mathrm{kg}^{-1}\right)$ por meio do método qualitativo, descrito por WILLIAMS \& EDWARDS (1980), a partir de cinco raízes de reserva tomadas ao acaso por parcela. A severidade da bacteriose foi aferida por meio da avaliação de três plantas por parcela, entre março e maio em cada safra, por meio da escala de notas descrita por RAMOS \& TAKATSU (1987), que varia de 1 a 5, em que: 1 = não há sintomas visíveis; 2 = há apenas manchas foliares; 3 = há manchas foliares e pus no caule; 4 = há manchas foliares, pus no caule e desfolha; e 5 = há morte descendente.

Para a determinação do teor de carotenoides nas raízes de reserva, no momento das colheitas, foram amostradas aleatoriamente em cada parcela seis raízes de reserva de cada acesso, sendo 
Tabela 1 - Relação dos acessos de mandioca avaliados com respectivos códigos do Banco de Germoplasma de Mandioca do Cerrado (BGMC), nomes comuns, estado de coleta/procedência (LCP) e coloração da polpa da raiz (CPR).

\begin{tabular}{|c|c|c|c|}
\hline Acessos & Nome comum & LCP & CPR \\
\hline BGMC 982 & IAPAR 19/Pioneira $^{1}$ & Paraná & creme \\
\hline BGMC 1415 & Vermelha & Distrito Federal & rosada \\
\hline BGMC 1228 & Mirassol & Mato Grosso & rosada \\
\hline BGMC 1222 & Colorada & Distrito Federal & rosada \\
\hline BGMC 1229 & Vermelha Omar & Distrito Federal & rosada \\
\hline BGMC 1218 & Klainasik & Pará & amarela \\
\hline BGMC 1221 & Xingu & Pará & amarela \\
\hline BGMC 1231 & Sem denominação & Maranhão & amarela \\
\hline BGMC 1398 & BRS Dourada $^{2}$ & Bahia & amarela \\
\hline BGMC 1223 & Oricuri & Pará & amarela \\
\hline BGMC 1224 & Surubim & Pará & amarela \\
\hline BGMC 1226 & AC Vermelha & Pará & amarela \\
\hline BGMC 1227 & Pretinha & Pará & amarela \\
\hline
\end{tabular}

${ }^{1}=$ Variedade de mandioca de mesa recomendada para o cultivo pelo programa de melhoramento genético de mandioca do Instituto Agronômico do Paraná (IAPAR), baseado em Londrina (PR).

${ }_{2}^{2}=$ Variedade de mandioca de mesa recomendada para o cultivo pelo programa de melhoramento genético de mandioca da Embrapa Mandioca e Fruticultura Tropical, baseado em Cruz das Almas (BA).

duas raízes de tamanho grande, duas de tamanho médio e duas pequenas, as quais foram identificadas, acondicionadas em saco plástico e imediatamente imersas em caixa térmica com gelo e encaminhadas para o laboratório.

No laboratório, sob baixa iluminação, as raízes foram lavadas em água corrente e cortadas em três cilindros de 2 a $3 \mathrm{~cm}$ de altura por 3 a $5 \mathrm{~cm}$ de diâmetro de cada raiz, sendo um central e dois nas extremidades das raízes, os quais foram divididos em quatro partes por meio de dois cortes longitudinais e homogeneizados. Cerca de $30 \mathrm{~g}$ de amostra foram então pesadas, identificadas e imediatamente congeladas em nitrogênio líquido, seladas a vácuo e armazenadas em freezer $-80^{\circ} \mathrm{C}$, para posterior análise. A extração de carotenoides foi realizada de acordo com o protocolo descrito por RODRIGUEZ-AMAYA (2001). Para a análise da absorbância, foi utilizado o espectrofotômetro SHIMADZU UV-Vis UV-1601 a uma varredura de 300 a $500 \mathrm{~nm}$, com leitura em $450 \mathrm{~nm}$. O teor de carotenoides em $\mu \mathrm{g} \mathrm{g}^{-1}$ (CT) foi estimado de acordo com a seguinte equação:

$\mathrm{CT}=\frac{\mathrm{A} \times \mathrm{V}(\mathrm{ml}) \times 10^{4}}{\mathrm{~A}_{1 \mathrm{~cm}}^{1 \% \mathrm{~F}} \times \mathrm{P}(\mathrm{g})}$, em que: $\mathrm{A}_{1 \mathrm{~cm}}^{1 \%}=2592$ (coeficiente de absorção do $\beta$-caroteno em éter de petróleo), $\mathrm{A}=$ absorvância, $\mathrm{V}=$ volume total do extrato e $\mathrm{P}=$ peso da amostra.

Os dados dos caracteres altura da planta, altura da primeira ramificação, massa da parte aérea, produtividade de raízes, porcentagem de amido nas raízes, severidade da bacteriose (médias transformadas para raiz quadrada da nota) e teor de carotenoides foram submetidos à análise de variância e a média da testemunha para cada caráter foi comparada com as médias dos demais acessos por meio do teste de comparação de médias DMS a 5\% de probabilidade de erro. As análises estatísticas foram realizadas com auxílio do programa Genes (CRUZ et al., 2001). Como os dados obtidos para os teores de ácido cianídrico nas raízes foram qualitativos, eles não foram utilizados nas análises estatísticas.

\section{RESULTADO E DISCUSSÃO}

Os resultados da análise de variância evidenciaram a existência de diferenças significativas entre os acessos a 5\% de probabilidade de erro para os caracteres altura da primeira ramificação, altura da planta, massa da parte aérea, produtividade de raízes, porcentagem de amido nas raízes, severidade de bacteriose e teor de carotenoides nas raízes, revelando a existência de variabilidade no grupo de acessos estudados (Tabela 2). O que pode ser explicado pelo fato de terem sido selecionados para o trabalho acessos de diferentes origens e estágios de melhoramento (Tabela 1).

A análise de variância também revelou a existência de diferenças significativas a 5\% de probabilidade de erro entre as safras e a existência de interação significativa entre acessos x safras para os caracteres: altura da primeira ramificação, altura da planta, massa da parte aérea, produtividade de raízes e 
Tabela 2 - Resumo da análise de variância e médias dos caracteres altura da primeira ramificação em m (APR), altura da planta em m (AP), massa da parte aérea sem a cepa em $\mathrm{kg} \mathrm{ha}^{-1}$ (MPA), produtividade de raízes $\mathrm{em} \mathrm{kg} \mathrm{ha}^{-1}$ (PR), porcentagem de amido nas raízes (AM), severidade de bacteriose (SB), teor de carotenoides nas raízes de reserva em $\mu \mathrm{g} \mathrm{g}^{-1} \mathrm{de}_{\text {massa fresca (CT), tempo para a }}$ cocção em minutos (TC) e o teor de ácido cianídrico nas raízes em $\mathrm{mg} \mathrm{kg}^{-1}(\mathrm{HCN})$, avaliados em treze acessos de mandioca, nas safras 2006/2007 e 2007/2008. tabelas para a Cr tem no máximo três linhas horizontais.

\begin{tabular}{|c|c|c|c|c|c|c|c|c|c|}
\hline Acesso & APR m & $\mathrm{AP} \mathrm{m}$ & MPA kg ha-1 & PR kg ha ${ }^{-1}$ & AM \% & $\mathrm{SB}^{1}$ & $\mathrm{CT} \mu \mathrm{g} \mathrm{g}^{-1}$ & $\mathrm{HCN}^{2} \mathrm{mg} \mathrm{kg}^{-1}$ & $\mathrm{TC}^{3} \min$ \\
\hline BGMC 982 & $0,88^{4}$ & 1,95 & 15548 & 25970 & 29,95 & 1,05 & 1,47 & $10-15$ & 25 \\
\hline BGMC 1415 & 0,83 & 1,88 & 13732 & $1644^{\mathrm{I}}$ & $19,60^{\mathrm{I}}$ & $1,83^{\mathrm{S}}$ & $18,42^{\mathrm{S}}$ & $15-25$ & $\mathrm{NC}$ \\
\hline BGMC 1228 & 0,87 & 1,97 & $20723^{\mathrm{S}}$ & $1292^{\mathrm{I}}$ & $22,57^{\mathrm{I}}$ & $1,81^{\mathrm{s}}$ & $19,18^{\mathrm{S}}$ & $15-25$ & $\mathrm{NC}$ \\
\hline BGMC 1222 & $0,25^{\mathrm{I}}$ & $1,35^{\mathrm{I}}$ & $12964^{\mathrm{I}}$ & $12928^{I}$ & $21,45^{\mathrm{I}}$ & $1,44^{\mathrm{S}}$ & $16,63^{\mathrm{S}}$ & $15-25$ & $\mathrm{NC}$ \\
\hline BGMC 1229 & $0,25^{\mathrm{I}}$ & $1,66^{\mathrm{I}}$ & $18329^{\mathrm{S}}$ & $10184^{\mathrm{I}}$ & $21,65^{\mathrm{I}}$ & $2,09^{\mathrm{S}}$ & $16,41^{\mathrm{S}}$ & $25-40$ & $\mathrm{NC}$ \\
\hline BGMC 1218 & $0,51^{\mathrm{I}}$ & $1,58^{\mathrm{I}}$ & $7362^{\mathrm{I}}$ & $5113^{\mathrm{I}}$ & $24,96^{\mathrm{I}}$ & $2,65^{\mathrm{s}}$ & $12,32^{\mathrm{S}}$ & $60-85$ & $\mathrm{NC}$ \\
\hline BGMC 1221 & $0,26^{\mathrm{I}}$ & $2,27^{\mathrm{S}}$ & 17444 & $7061^{\mathrm{I}}$ & $27,51^{\mathrm{I}}$ & 1,00 & $11,87^{\mathrm{S}}$ & $85-115$ & $\mathrm{NC}$ \\
\hline BGMC 1231 & 0,79 & 1,82 & $10074^{\mathrm{I}}$ & $13751^{\mathrm{I}}$ & $23,17^{\mathrm{I}}$ & $2,21^{\mathrm{S}}$ & $3,45^{\mathrm{s}}$ & $25-40$ & $\mathrm{NC}$ \\
\hline BGMC 1398 & 0,90 & 1,91 & $10110^{\mathrm{I}}$ & $14415^{\mathrm{I}}$ & $23,84^{\mathrm{I}}$ & $2,77^{\mathrm{S}}$ & $3,40^{\mathrm{S}}$ & $25-40$ & $\mathrm{NC}$ \\
\hline BGMC 1223 & $0,57^{\mathrm{I}}$ & 1,83 & $18810^{\mathrm{S}}$ & $8610^{\mathrm{I}}$ & $26,85^{\mathrm{I}}$ & $2,22^{\mathrm{S}}$ & $10,90^{\mathrm{S}}$ & $85-115$ & $\mathrm{NC}$ \\
\hline BGMC 1224 & 1,02 & 2,10 & 15587 & $8575^{\mathrm{I}}$ & $25,09^{\mathrm{I}}$ & $3,31^{\mathrm{s}}$ & $12,10^{\mathrm{S}}$ & $85-115$ & $\mathrm{NC}$ \\
\hline BGMC 1226 & $0,51^{\mathrm{I}}$ & $2,53^{\mathrm{S}}$ & $39268^{\mathrm{S}}$ & $4991^{\mathrm{I}}$ & $21,54^{\mathrm{I}}$ & $1,84^{\mathrm{S}}$ & $8,36^{\mathrm{S}}$ & $85-115$ & $\mathrm{NC}$ \\
\hline BGMC 1227 & $0,35^{\mathrm{I}}$ & 1,76 & $12785^{\mathrm{I}}$ & $7624^{I}$ & $32,83^{\mathrm{S}}$ & $3,93^{\mathrm{S}}$ & 2,31 & $85-115$ & $\mathrm{NC}$ \\
\hline Amplitude $^{5}$ & 0,77 & 1,18 & 31906 & 24678 & 13,23 & 2,93 & 17,71 & - & - \\
\hline \multicolumn{10}{|l|}{ FV (GL) } \\
\hline $\mathrm{QM}_{\text {Acessos }}(12)$ & $0,47^{* 6}$ & $0,54^{*}$ & $355800812^{*}$ & $252672042^{*}$ & $84,93^{*}$ & $0,49^{*}$ & $236^{*}$ & - & - \\
\hline $\mathrm{QM}_{\text {Safras }}(1)$ & $0,29^{*}$ & $1,92^{*}$ & $1835375853^{*}$ & $134162516^{*}$ & $9,28^{*}$ & 0,21 & 0,89 & - & - \\
\hline $\mathrm{QM}_{\mathrm{AxS}}(12)$ & $0,04^{*}$ & $0,12^{*}$ & $82888798^{*}$ & $27962010^{*}$ & $33,87^{*}$ & 0,01 & 0,17 & - & - \\
\hline $\mathrm{QM}_{\text {Resíduo }}(48)$ & 0,01 & 0,01 & 1523293 & 952888 & 0,60 & 0,02 & 0,70 & - & - \\
\hline CV (\%) & 13,43 & 6,09 & 7,40 & 10,39 & 3,13 & 10,67 & 7,96 & - & - \\
\hline DMS (5\%) & 0,14 & 0,19 & 2026 & 1602 & 1,27 & 0,06 & 1,37 & - & - \\
\hline
\end{tabular}

Análise de variância realizada com médias transformadas e médias originais apresentadas na tabela; 2 - aferido no momento da colheita por meio do método qualitativo, descrito por WILLIANS \& EDWARDS (1980); 3 - raízes não cozinharam em 30 minutos; 4- médias seguidas por S e I, nas colunas, são superiores ou inferiores, respectivamente, à média da testemunha BGMC 982 a $5 \%$ de probabilidade de erro pelo teste de comparação de médias DMS; 5 - diferença entre a maior e a menor média; 6- Quadrado médio (QM), seguido por (*) significativo a $5 \%$ de probabilidade de erro pelo teste $\mathrm{F}$.

porcentagem de amido nas raízes, demonstrando que a ordem de classificação dos acessos sofreu influência do efeito safra, em função dos acessos terem apresentado respostas diferenciadas as mudanças ambientais (Tabela 2). O que justifica a necessidade da avaliação dos acessos por mais de um ano, para a obtenção de uma estimativa segura da expressão final desses caracteres, como já havia sido relatado em mandioca por BORGES et al. (2002); VIDIGAL FILHO et al. (2000).

Entretanto, para os caracteres severidade da bacteriose e teor de carotenoides, não foram detectadas variações significativas a $5 \%$ de probabilidade de erro para os fatores safra e interação acessos x safras, indicando que os acessos não apresentaram respostas diferenciadas em razão do efeito safra para esses caracteres (Tabela 2). Uma possível explicação para a inexistência de influência do fator safra na manifestação da severidade da bacteriose, no presente trabalho, pode ser o fato de terem sido avaliados acessos contrastantes para o caráter em um local extremamente favorável à manifestação da moléstia, o que permitiu a diferenciação dos acessos quanto ao caráter em apenas um ano de avaliação.

A inexistência de influência do fator safra sobre o caráter teor de carotenoides apontou no sentido de não haver a necessidade de condução de experimentos por vários anos para se estimar com precisão o caráter. Isso pode representar economia de tempo e de dinheiro em programas de melhoramento genético de mandioca de mesa. Entretanto, novos estudos devem ser conduzidos a fim de determinar a influência conjunta dos fatores safra e locais de experimentação, bem como da idade de colheita, na manifestação do caráter. Uma vez que as variações de quantidades de carotenoides, dentro de uma mesma espécie, podem ser ocasionadas por fatores genéticos e por fatores ambientais, como solo, clima, temperatura, estação do ano, luminosidade e época de colheita (RODRIGUES-AMAYA, 2001).

O caráter tempo para o cozimento não foi considerado na análise de variância, uma vez que apenas a variedade utilizada como testemunha (BGMC 982/IAPAR 19) apresentou tempo para o 
cozimento inferior a 30 minutos em ambos os anos de avaliação. Esse resultado é um indicativo que as raízes dos demais acessos avaliados não apresentaram qualidades culinárias para a comercialização como mandioca de mesa, uma vez que variedades de mesa devem apresentar tempo para o cozimento inferiores a 30 minutos, massa cozida uniforme, sem fibras e com consistência plástica e moldável (LORENZI et al., 1994; FUKUDA et al., 2002).

No grupo de acessos avaliados, foi detectada ampla variação para os caracteres altura da primeira ramificação e altura da planta, ambos importantes para a seleção de variedades em função de estarem intimamente relacionados com a arquitetura da planta, com amplitudes de variação de, respectivamente, $0,77 \mathrm{~m}$ e $1,18 \mathrm{~m}$ (Tabela 2). O caráter altura da primeira ramificação é muito importante no melhoramento de mandioca, por estar relacionado à facilidade de tratos culturais, facilidade de plantio mecanizado e facilidade de colheita, sendo preferidos os acessos que apresentam maiores altura da primeira ramificação ou que não apresentem ramificação (VIDIGAL FILHO et al., 2000; FUKUDA et al., 2002). Para esse caráter, não foram identificados acessos com médias superiores à da testemunha BGMC 982, entretanto foram identificados seis acessos com médias estatisticamente iguais à da testemunha (BGMC 1224, BGMC 1328, BGMC 1228, BGMC 1415 e BGMC 1231), o que é um indicativo de que, para esse caráter, existem, no grupo de acessos avaliados, materiais com boa altura da primeira ramificação. Para a altura da planta, foram identificados dois acessos superiores estatisticamente à testemunha BGMC 1226 e BGMC 1221, com alturas superiores a 2,20m (Tabela 2).

Para a massa da parte aérea, foi identificada a amplitude de variação de $31906 \mathrm{~kg} \mathrm{ha}^{-1}$, tendo sido identificados quatro acessos com médias superiores estatisticamente à da testemunha BGMC 1226, BGMC 1228, BGMC 1223 e BGMC 1229 (Tabela 2). Esse caráter é importante por estar relacionado com o fornecimento de manivas-sementes para novos plantios, cobertura do solo e quanto à utilização da parte aérea da mandioca como fonte de proteína na alimentação animal (VIDIGAL FILHO et al., 2000; AZEVEDO et al., 2006).

A porcentagem de amido nas raízes apresentou amplitude de variação de 13,23\% e apenas o acesso BGMC 1227 com média superior à da testemunha (Tabela 2). A porcentagem de amido nas raízes, apesar de ser mais importante na seleção de materiais para a indústria, tem importância no melhoramento de mandioca de mesa, quando se pensa no aproveitamento das raízes também na produção de farinha e fécula.

No experimento, foi detectado apenas um acesso (BGMC 1221) com severidade da bacteriose semelhante à da testemunha, tendo todos os demais acessos revelado severidade da bacteriose superiores à da testemunha, o que compromete a possível indicação de algum dos demais acessos para o cultivo na região do Cerrado (Tabela 2).

O mesmo cenário foi observado para a produtividade de raízes, uma vez que todos os acessos avaliados apresentaram médias inferiores à da testemunha (Tabela 2), revelando que nenhum dos acessos avaliados apresenta potencial produtivo nas condições de realização do experimento.

Já para os teores de ácido cianídrico nas raízes de reserva, cinco acessos (BGMC 1221, BGMC 1223, BGMC 1224, BGMC 1226 e BGMC 1227) revelaram teores de ácido cianídrico nas raízes superiores a $100 \mathrm{mg} \mathrm{kg}^{-1}$ (Tabela 2), portanto sendo impróprios para a comercialização como vegetal fresco. Entretanto, esses acessos podem ser utilizados como genitores no melhoramento genético, uma vez que é possível a seleção de clones com baixos teores de ácido cianídrico nas raízes, mesmo em progênies oriundas de acessos com elevados teores de ácido cianídrico nas raízes (VALLE et al., 2004).

Quanto ao teor de carotenoides, todos os acessos, com exceção do BGMC 1227, apresentaram teor de carotenoides superiores estatisticamente ao da testemunha (Tabela 2), revelando que, no grupo de acessos avaliados, existem fontes de genes para se elevar o teor de carotenoides em raízes de mandioca. Dentre os acessos estudados, os com coloração da polpa das raízes rosadas, BGMC 1228, BGMC 1415, BGMC 1222 e BGMC 1229, foram os que apresentaram as maiores médias de teor de carotenoides, com, respectivamente, 19,18, 18,42, 16,63 e $16,41 \mu \mathrm{g} \mathrm{g}^{-1}$ de massa fresca (Tabela 2). A presença de maiores teores de carotenoides em raízes de reserva mandioca de coloração rosada, em relação às de coloração amarela e creme provavelmente seja decorrência do fato de acumularem licopeno e $\beta$-caroteno em suas raízes de reserva (CARVALHO et al., 2012b).

Dentre os acessos com coloração da polpa das raízes amarelas, os que apresentaram médias de teor de carotenoides nas raízes superiores a $10 \mu \mathrm{g} \mathrm{g}^{-1}$ de massa fresca foram BGMC 1218, BGMC 1224, BGMC 1221 e BGMC 1223. Os demais acessos com teor de carotenoides superiores ao da testemunha apresentaram médias que variaram de 3,40 a $8,36 \mu \mathrm{g}$ $\mathrm{g}^{-1}$ de massa fresca (Tabela 2). Resultado semelhante 
foi relatado por CHÁVEZ et al. (2005) após analisar mais de 1700 acessos do banco de germoplasma de mandioca do Centro Internacional de Agricultura Tropical (CIAT) da Colômbia, em que os teores de carotenoides variaram 1,02 a $10,40 \mu \mathrm{g} \mathrm{g}^{-1}$. Já MEZETTE et al. (2009), ao analisarem 13 clones elite de mandioca, relataram valores de carotenoides variando de 3,30 a $11,08 \mu \mathrm{g} \mathrm{g}^{-1}$. O teor de carotenoides pode ser considerado um bom indicativo do teor de betacaroteno em raízes de reserva de mandioca, uma vez que estudos vêm revelando que em média $70 \%$ dos teores de carotenoides correspondem ao $\beta$-caroteno (MEZZETE et al., 2009; CARVALHO et al., 2012b).

Com base nos resultados obtidos, é possível afirmar que, no grupo dos acessos avaliados, nenhum apresenta desempenho agronômico que permita o seu cultivo de forma comercial na região do Cerrado do Brasil Central. Entretanto, é provável que, dentre os acessos avaliados, existem genótipos com potencial para utilização como genitores no melhoramento da cultura, visando ao aumento dos teores de $\beta$-caroteno e de licopeno em raízes de reserva. Nesse sentido, destacaram-se como possíveis genitores para o melhoramento, visando ao aumento dos teores de licopeno nas raízes, os acessos com coloração da polpa da raiz rosada BGMC 1222 e BGMC 1229, em cruzamento com genótipos adaptados às condições do Cerrado. Também se destacaram os acessos com coloração da polpa da raiz amarela BGMC 1221, BGMC BGMC 1223 e BGMC 1224, também em cruzamentos com constituições genéticas adaptadas às condições do Cerrado do Brasil Central, para que, dessa forma, o sistema de produção de mandiocas de mesa biofortificadas seja viabilizado na região.

\section{CONCLUSÃO}

No grupo de acessos avaliados nenhum apresentou desempenho agronômico que justifique o seu cultivo de forma comercial na região do Cerrado do Brasil Central. Entretanto foram detectados acessos com potencial para utilização como genitores no melhoramento da cultura, visando ao incremento dos teores de $\beta$-caroteno BGMC 1221, BGMC BGMC 1223 e BGMC 1224 e de licopeno BGMC 1222 e BGMC 1229 em raízes de reserva.

\section{AGRADECIMENTOS}

À Empresa Brasileira de Pesquisa Agropecuária (Embrapa), à Fundação Banco do Brasil e ao Conselho Nacional de Desenvolvimento Científico e Tecnológico (CNPq), pelo apoio financeiro; à assistente da Embrapa Cerrados, Sayuri Cristina Takada da Silva, pelo auxílio nas análises bioquímicas.

\section{REFERÊNCIAS}

AZEVEDO, E.B. et al. Silagem da parte aérea de cultivares de mandioca. Ciência Rural, v.36, p.1902-1908, 2006. Disponível em: $<$ http://dx.doi.org/10.1590/S0103-84782006000600037>. Acesso em: 22 abr. 2013. doi: 10.1590/S0103-84782006000600037.

BORGES, M.F. et al. Avaliação de variedades de mandioca para consumo humano. Pesquisa Agropecuária Brasileira, v.37, p.1559-1565, 2002. Disponível em: <http://dx.doi.org/10.1590/ S0100-204X2002001100006>. Acesso em: 22 abr. 2013. doi: 10.1590/S0100-204X2002001100006

CARVALHO, L.J.C.B. et al. Characterization of carotenoidprotein complexes and gene expression analysis associated with carotenoid sequestration in pigmented cassava (Manihot esculenta Crantz) storage root. Open Biochemistry Journal, v.6, p.116-130, 2012a. Disponível em: <http://www.benthamscience.com/open/ tobiocj/articles/V006/116TOBIOCJ.pdf>. Acesso em: 22 abr. 2013. doi: 10.2174/1874091X01206010116.

CARVALHO, L.M.J. et al. Retention of total carotenoid and ß-carotene in yellow sweet cassava (Manihot esculenta Crantz) after domestic cooking. Food \& Nutrition Research, v.56, 15788, 2012a. Disponível em: <http://www.foodandnutritionresearch.net/ index.php/fnr/article/view/15788>. Acesso em: 22 abr. 2013. doi: 10.3402/fnr.v56i0.15788.

CARVALHO, L.J.C.B. et al. A genomic assisted breeding program for cassava to improve nutritional quality and industrial traits of storage root. Crop Breeding and Applied Biotechnology, v.11, p.289-296, 2011. Disponível em: <http://dx.doi.org/10.1590/ S1984-70332011000400001>. Acesso em: 22 abr. 2013. doi: 10.1590/S1984-70332011000400001.

CHÁVEZ, A.L. et al. Variation of quality traits in cassava roots evaluated in landraces and improved clones. Euphytica, v.143, p.125-133, 2005. Disponível em: $<$ http://link.springer.com/article/ 10.1007\%2Fs10681-005-3057-2>. Acesso em: 22 abr. 2013. doi: $10.1007 / \mathrm{s} 10681-005-3057-2$.

CRUZ, C.D. Programa genes: aplicativo computacional em genética e estatística. Viçosa: UFV, 2001. 648p.

FIALHO, J.F.; VIEIRA, E.A. Manejo e tratos culturais da mandioca. In: FIALHO, J.F.; VIEIRA, E.A. (Ed.). Mandioca no cerrado: orientações técnicas. Planaltina: Embrapa Cerrados, 2011. p.60-91.

FUKUDA, W.M.G. et al. Cassava breeding. Crop Breeding and Applied Biotechnology, v.2, p.617-638, 2002. Disponível em: $<$ http://www.sbmp.org.br/cbab/siscbab/modules/news/makepdf. php?storyid=139>. Acesso em: 22 abr. 2013.

GROSMANN, J.; FREITAS, A.G. Determinação do teor de matéria seca pelo método peso específico em raízes de mandioca. Revista Agronômica, v.14, p.75-80, 1950

LORENZI, O.J. Variação na qualidade culinária das raízes de mandioca. Bragantia, v.53, p.237-245, 1994. Disponível em: $<$ http://www.scielo.br/pdf/brag/v53n2/13.pdf>. Acesso em: 22 abr. 2013

MEZETTE, T.F. et al. Seleção de clones-elite de mandioca de mesa visando a características agronómicas, tecnológicas e químicas. Bragantia, v.68, p.601-609, 2009. Disponível em: <http://dx.doi. 
org/10.1590/S0006-87052009000300006>. Acesso em: 22 abr. 2013. doi: 10.1590/S0006-87052009000300006.

RAMOS, J.G.A.; TAKATSU, A. Avaliação da resistência de cultivares de mandioca à bacteriose em Goiás. Goiânia: EMGOPA, 1987. $26 \mathrm{p}$.

RODRIGUEZ-AMAYA, D.B. A guide to carotenoid analysis in food. Washington: OMNI Research, 2001. 64p.

SHAMI, N.J.I.E.; MOREIRA, E.A.M. Licopeno como agente antioxidante. Revista de Nutrição, v.17, p.227-236, 2004. Disponível em: <http://dx.doi.org/10.1590/S1415-52732004000200009>. Acesso em: 22 abr. 2013. doi: 10.1590/S1415-52732004000200009.

UNDERWOOD, B.A.; SMITASII, S. Micronutrient malnutrition: policies and programs for control and their implications. Annual Review of Nutrition, v.19, p.303-324, 1999. Disponível em: $<$ http://www.annualreviews.org/doi/pdf/10.1146/annurev. nutr.19.1.303>. Acesso em: 22 abr. 2013. doi: 10.1146/annurev. nutr.19.1.303.

VALLE, T.L. et al. Conteúdo cianogênico em progenies de mandioca originadas do cruzamento de variedades mansas e bravas. Bragantia, v.63, p.221-226, 2004. Disponível em: <http://
dx.doi.org/10.1590/S0006-87052004000200007>. Acesso em: 22 abr. 2013. doi: 10.1590/S0006-87052004000200007.

VIDIGAL FILHO, P.S. et al. Avaliação de cultivares de mandioca na região noroeste do Paraná. Bragantia, v.59, p.6975, 2000. Disponível em: <http://dx.doi.org/10.1590/S000687052000000100011>. Acesso em: 22 abr. 2013. doi: 10.1590/ S0006-87052000000100011

VIEIRA, E.A. et al. Caracterização molecular de acessos de mandioca biofortificados com potencial de uso no melhoramento genético. Revista Ciência Agronômica, v.42, p.457-463, 2011. Disponível em: $<\mathrm{http}$ //dx.doi.org/10.1590/S1806-66902011000200027>. Acesso em: 22 abr. 2013. doi: 10.1590/S1806-66902011000200027.

VIEIRA, E.A. at al. Comportamento de genótipos de mandioca de mesa no Distrito Federal. Ciência Agronômica, v.40, p.113-122, 2009. Disponível em: <http://ccarevista.ufc.br/seer/index.php/ ccarevista/article/view/412/308>. Acesso em: 22 abr. 2013.

WILLIAMS, H.J.; EDWARDS, T.G. Estimation of cyanide with alkaline picrate. Journal of the Science of Food and Agriculture, v.31, p.15-22, 1980. Disponível em: <http://onlinelibrary.wiley. com/doi/10.1002/jsfa.2740310104/abstract>. Acesso em: 22 abr. 2013. doi: $0.1002 /$ jsfa.2740310104. 